\title{
ЛОГИКА ГАРМОНИЗАЦИИ ЛИЧНОСТНОГО БЫТИЯ ЧЕЛОВЕКА
}

\section{И.В. Шевченко}

Достижение знания об устройстве собственной жизни, жизненного мира и оценивание значимости «человеческих действий и взаимодействий» (П. Сорокин), требует проникновения в суть и структуру социокультурных явлений жизнебытийности человека и социума. Эти явления, по мнению П.Сорокина, включают в себя, во-первых, «мыслящих, действующих и реагирующих людей, являющихся субъектами взаимодействия». Во-вторых, «значения, ценности и нормы, благодаря которым индивиды взаимодействуют, осознавая их и обмениваясь ими». Наконец, «открытые действия и материальные артефакты как двигатели или проводники, с помощью которых объективируются и социализируются нематериальные значения, ценности и нормы» [9, с. 193]. Составляющие жизненный мир индивида как сущее, последние, собственно, и предстают «непосредственным самобытием» (С.Франк), самотворением человека, ассимилирующим многообразие бытия в собственную логику жизнеосуществления.

Вместе с тем, «включенность» человека в контекст жизнеосуществления не всегда является творческим процессом идентификации и самоосуществления в тенденции к устроению (гармонизации) жизни. Как показывает практика, не всем субъектам жизнетворения присуще стремление исполнить «жгучую потребность реализации себя в совершенном акте бытия» (А. Менегетти). Люди «со слабым импульсом к жизни» (Г. Гессе) «тяготам» творчества предпочитают ту или иную форму онтологической неангажированности: пассивность, жизнь без напряжения, стилизаторство, конформизм и т.п.

Однако подобного рода «устроение» жизни представляет собой жизненное квазиравновесие. «Вселенная в своих онтологических основах является творческой и такого же творческого ответа ждет от человека» $[8$, c. 7]. То есть, деятельным основанием гармонизации человеческого бытия 
есть онтологическая имманентность, присущая всему живому и определяющая индивидов как самодетерминанта, нацеливающая, устремляющая их к саморегуляции и экзистенциальной самоактуализации в жизненном мире.

Исходя из этого, можно утверждать: каков жизненный мир человека, каков его индивидуальный жизненный опыт, ценностная ориентация, содержание мыслей, чувств и настроений, таков и сам человек. Человек не «пригнан» изначально к миру, социуму, истории. Подобную «пригнанность» к миропорядку человек начинает с адаптации к миру, создавая свой собственный витальный жизненный мир. Однако уже даже сотворение обыденного жизненного мира не укладывается в рамки повседневного житейского опыта. Устроение жизни требует от человека неожиданных решений с помощью мыслительных и образных средств, способов креативного миропостижения и иных скрытых возможностей, проявляющихся в различных практических творческих манифестациях. Творчество в таком смысле является самой значительной атрибутивной характеристикой человека, что отражает его «родовую сущность», реализуемую через социокультурную активность.

Основополагающей характеристикой творческого отношения человека к миру и к жизненному миру научно-философская мысль полагает новизну, определяя творчество как деятельность по сотворению нового. И особенность новаторства, с одной стороны, состоит в отрицании старого, консервативного, традиционного. С другой, установление нового всегда связано с наследованием прошлого, удерживанием и сохранением наиболее рациональных моментов последнего, с критически-выборочным характером оценочной деятельности субъектов творческих преобразований. Следовательно, старое и новое, репродуктивное и продуктивное объединены в творчестве самым тесным образом.

Именно поэтому, существенным недостатком традиции рассмотрения творчества, на наш взгляд, есть то, что не всегда учитывается его противоречивая природа: одновременное созидание, разрушение и воспроизведение сущего как вех, пройденного миром и человеком пути его анализа и оценки. Творчество - атрибут человеческой жизнедеятельности, показатель культуры жизнетворения и духовного самообретения личности, неотъемлемое свойство ее сознания, деятельных актов преобразования, устроения и переустройства мира и собственного жизненного мира, разрешения проблемных ситуаций жизни, освоения ценностей культуры, то есть всеобъемлющий, универсальный способ овладения жизнестроительством.

Следовательно, наиболее существенной стороной универсального жизнетворческого процесса является устроение нового жизненного мира усовершенствование, преобразование, «приращение», «прибавление», «re- 
praesentatio» [3, с. 305] жизни как сущего. В оценке украинских философов В. Иванова, А. Канарского, А. Яценко такое творчество есть, по преимуществу, «ценностно-процессуальным феноменом» (А. Канарский), проявляющим сущность человека и обуславливающим его развитие и саморазвитие, гармонизацию отношений человека с миром в целом и гармоничность его внутреннего духовного мира. Творчество как детерминанта устроения индивидуальной жизни лишь тогда выполняет свое субстанциальное предназначение, когда обуславливает позитивно-значимую меру бытийных преобразований, опредмечивание и распредмечивание личностью всего богатства социокультурных смыслов, составляющих содержание духовной жизни общества.

Таким образом, уточнение содержания сущностной характеристики творчества позволяет нам, вслед за авторами работы «Жизненный путь личности»-украинскими философами Е. Донченко, Е. Злобиной, М. Недашковской, Л. Сохань, В. Тихоновичем и др., определить упорядочение собственной жизни человека «особым видом творчества - жизнетворчеством», жизнетворением [4, с. 42]. Еще раз подчеркнем, что жизнетворчество, жизнетворение характеризуется одновременным единством и взаимодействием процессов созидания и самосозидания, со-творения общечеловеческого бытия, культуры и самотворения человеком своего собственного жизненного мира. Следовательно, жизнетворчество предстает интенцией личности, главное в которой-не получение новых материальных и духовных благ, а постоянное преобразование жизненного мира личности, созидание новых жизненных смыслов, определяемых ценностно-смысловым и духовным основанием личностного жизнеустроения сбалансированной системой социальных, общечеловеческих и экзистенциальных ценностей. При этом необходим учет позитивных экзистенциальных изменений, развития задатков, дарований и способностей, то есть, всего того, что повышает жизнеустроительную потенциальную значимость субъекта собственной жизнебытийности, детерминирующих ее гармоничность, превращение в «произведение» жизнетворчества.

Следовательно, жизнетворение - это бытийная миссия экзистенции, основание всех жизнеустроительных объективаций, проявление человеческой креативной сущности удовлетворяющего свойства. С другой стороны, жизнетворчество личности детерминировано гармонической целостностью социокультурного миропорядка, абсолютным условием бытийности которого есть гармония как жизнеустроительный принцип, наиболее адекватный способ устроения человеческой жизни. В таком смысле «гармония и есть творящая логика» жизни [2, с. 23], суть которой состоит в установлении равновесия между объективными запросами и субъективными ресурсами людей и сохранении при этом порядка в рамках изменений. Вследствие такой «творящей логики» все сущее в снятом виде нахо- 
дится в человеческой личности как в индивидуализированном поливерсуме, обеспечивая не просто ощущение внешней связанности, но и внутренней сопричастности бытию как единому. Тем самым, творчество-жизнетворение предстает взаимодетерминированным единством, целостностью человеческого жизненного порядка.

Субъектом всех, даже незначительных и малозаметных жизнебытийных артикуляций, носителем жизнетворческой силы, которая способна «сама» «измерять» и «определять» «качество» жизнетворения, «осваивать» и «осваиваться», «обживать» и «обживаться» в мире, выбирать свое место в нем, осознавать детерминирующие жизненный мир гармонизирующие экзистенциалы и основополагающие конструкты устроения его целостности, носителем интегрального аналога «конституирующей интенциональности» (Э. Гуссерль) выступает индивидуализированный субъект жизнетворения, конкретная человеческая личность, личность-творец, разумное природное и общественное существо, жизнедеятельность которого предопределена, в том числе, гармоническим единством его способностей, наклонностей, психики, воли, характера, мотивов и т.п.

Вместе с тем, индивид как субъект жизнетворения не есть простая сумма выше приведенных характеристик. Его неисчерпаемая жизнетворческая активность полагает природный, социальный, культурный и духовный миры «объектом» приложения своих жизнеустроительных интенций. Следовательно, «субъект» жизнетворения «является объектом собственной активности» [6, с. 43], а жизнетворчество - ни чем иным, как субъект-объектной интегративно-динамической целостностью. То есть, изменяя свое отношение к миру, субъект жизнетворения тем самым всегда изменяет отношение мира к себе, ибо мир действует на человека так, а не иначе именно потому, что человек действует на мир определенным образом. Другими словами, индивидуальное жизнетворение «напряжено идеей» творческой «личности» [2, с. 329].

Что значит быть творческой личностью? Прежде всего, это быть самостью, «solo»-самоидентичной, самодостаточной и самоактуализирующейся, свободной, неповторимой и сущностно-содержательной индивидуальностью. Никого нельзя заставить быть творцом своей жизни. Это дело выбора самого индивида, его самосознание, самосозидание и самотворение. Поэтому, уникальность человеческого индивида в поливерсуме живых существ состоит в том, что это единственное существо, которое «само» «может стать» или «может сделать» «себя» творческой личностью, автором и инициатором последовательно организованного ряда жизненных событий. Может стать «творческим центром» (Н. Кузанский) самотворения и самоутверждения в индивидуальном, самостоятельном, самодостаточном и самоидентичном (гармоничном) существовании. Таким образом, основой и способом творческого экзистирования личности 
является ее способность к самоосуществлению, а залогом продуктивности последнего - осознанность выявления и утверждения жизнеосуществления, как актов самоорганизации.

С другой стороны, жизнетворческая личность не может существовать в «себе самой». «Личность-творец» проявляется лишь тогда, когда «расплавляется и побеждается затверделая самость» (Н. Бердяев). Когда самость выходит из «себя самой» и «прорастает в мир жизни» (А. Лосев), в «бытие-для-другого», «вручая себя» (Ю. Лотман) общезначимым целям и смыслам. Интериоризация и следование им в повседневной жизни создают чувство укорененности, опоры и защищенности личности в пространстве ее жизненного мира. Социально значимое содержание смыслов, жизнетворческие цели и устремления максимально воодушевляют человека, активизируют его жизненную энергию и способности, обусловливают гармоничный жизненный мир. Следовательно, в процессе жизнетворения важно как можно больше «освоить» заложенные в человеке возможности и, тем самым, обрести сущностную, человеческую индивидуальную «определенность» как всеобщность.

В этом смысле личность - «не единичное и даже не особенное, а монадное образование... » [7, с. 39], способность представлять себя, свое время, свой народ, национальную культуру. Раскрывая бытие социального в индивидуальном и через индивидуальное, равно как становление и пребывание индивидуального в социальном и через социальное, творческая личность обретает свою особую, специфически человеческую форму существования. Эта специфически человеческая форма существования предстает как интегративно-динамическое единство (гармония) подлинности и смысла человеческого экзистирования в пространстве действия законов социокультурогенеза.

Восхождение к такому единству - всегда тяжкий труд и духовное борение, совершающееся в конкретных бытийных условиях, накладывающих свои ограничения и сообщающих многочисленные противоречия системе «мир-человек». Эти противоречия есть всегда и непреходящи, но вместе с тем конструктивны и заключают в себе возможность их гармонического разрешения. Перед лицом препятствий человек повышает требовательность к самому себе и, в первую очередь, к себе как человеку, ибо сам «пишет» свой «портрет», свое истинное «лицо» самой своей жизнью. И как личность, он должен все преодолеть: подняться мыслью над всем и над собой, действуя не «во властной субъективности» (С. Крымский), а в соответствие с логикой личностного жизнеустроения, достигая в процессе жизнетворения согласованности с самим собой и бытием в целом.

Поэтому жизнетворческое экзистирование личности есть ни что иное как непрестанная борьба с самим собой в осознании собственньх слабостей, несовершенства и несоответствия высоте истинности человеческого 
призвания, «великое внутреннее делание» себя. В качестве примера внутренней индивидуальной работы над собой, как личностной интенциональности, может рассматриваться человеческое «своенравие» (Г. Гессе). Основанное на мотивации и логике избранности, «своенравие» означает, что «у субъекта нет алиби, связанного с возможностью переложить бремя своей уникальной ответственности на другого» [8, с. 10] за выбор своего образа жизни.

Такая жизнетворческая личность наиболее полно отражается в идее «Homo cultures», где «человек культуры» есть и «высшая инстанция в человеке» (З. Фрейд), и сам человек как высшее существо. Его активная деятельность, в первую очередь, снимает дисгармонию самосознания, устраняя, таким образом, самоотчуждение в артикуляциях самореализации и самопроявления как непрекращающегося преодоления себя в стремлении к совершенству и господству над самим собой, в обретении действительности своего жизненного мира как «мира жизненной культуры» [11]. Причем заметим, «Homo cultures»- это не новый тип человеческой личности, а специфически человеческая возможность самореализации в жизнетворческом процессе, проявление своей человеческой сущности. Преодолевая себя, «обыденный» человек устремляется к человеку «истинному», «культурному», являющемуся вершиной эволюции рода «Homo sapiens» и идеальным воплощением саморазрушения в человеке «твари» и созидания в нем «творца» (Ф.Ницше).

То есть, человека «вообще» от человека жизнетворческого отделяют не только обстоятельства, время, история. Его отделяет и собственная неподготовленность к принятию нового уровня экзистирования - целостной и устойчивой системы саморазвития и самопроявления интегративно-динамической субстанциальности человеческого «Я», устремленного к гармоническому единству свободы мысли, чувств и действий.

Свобода, таким образом, предстает неотъемлемым атрибутом жизнетворческой устремленности человека, возможности его самореализации, проявления себя и особенностей своей личности в креативных актах собственного выбора и ответственности. Она определяет сущностную характеристику творчества вообще и жизнетворчества в особенности, его подлинный смысл в равной степени как принцип творчества - основную характеристику и подлинный смысл свободы.

Следовательно, творческим может быть названо только то жизненное деяние, которое осуществляется свободно. Соответственно, наиболее адекватным способом реализации гармоничности личностного жизнетворения есть свободное жизнетворение. Ибо свободное жизнетворение актуализирует выбор безграничности жизнетворческих целей и возможностей человека, социокультурную необходимость, законосообразность и личную ответственность за свою судьбу, упорядоченность или неупорядоченность, 
логику или отсутствие таковой в устроении своей жизни.

То есть, в процессе жизнетворения особое значение приобретает проблема соотнесенности свободы, возможности, необходимости, законосообразности и целесообразности. Так, традиционный антропологизм, базирующийся на максиме, что человек свободен в рамках внешней (объективной) необходимости, определяет свободу как познанную необходимость и как деятельность со знанием дела (Спиноза, Гегель, Энгельс). Однако, разве «свобода, которая будет результатом необходимости», то есть, показателем потенциального принуждения, «будет подлинной свободой» $[1$, с. 51]? Такая «свобода», - по Н. Бердяеву, - становится фактором человеческой не-свободы.

Подлинная сущность свободы может рассматриваться, очевидно, в пространстве одной «четверти свободы на фоне „трех четвертей необходимости“" $[5$, с. 8], в пространстве объективной заданности и жизнетворческой независимости человека как возможности, необходимости, законо- и целесообразности «выхода» за пределы механистического детерминизма. Механизм такого «выхода» зиждется на пространстве свободы, которая не только задана извне, но и внутренне обретена личностью как способность «создавать свободу» из себя «для себя», как свою «внутреннюю свободу» (И.ККант). Тем самым, горизонты свободы, определяемые жизнетворческими основаниями и смыслами, видятся не в освоении всего объема внешней свободы, а в созидании свободы внутри себя. Осознание именно этой, «внутренней свободы» обеспечивает человеку автономность и независимость в мире внешней детерминации как возможности опредмечивания бесконечности творческих возможностей человеческого жизнетворения в «добавлении», «достраивании» всеобего культурно-исторического творчества.

Однако, как оказалось из опыта позднего модерна, человек может и злоупотреблять свободой. Следовательно, сегодня важна не свобода как таковая, а культура свободы. Поскольку лишь культура свободы может очерчивать как возможность вариативности жизнетворения, так и необходимость ее целе- и смыслосообразности в виде «необратимого потока «очеловеченного» бытия» [10, с. 84], где действует единая системная целостность «Человек-Жизненный мир». В рамках этой целостности «человек не выступает более эпифеноменом какой бы то ни было сущности материи, идеального субъекта творчества, общественных отношений. Он самодостаточная часть целого, самоценная монада в общей структуре бинаправленно действующих монад» [10, с. 207]. То есть, с одной стороны, имманентно присущая человеку возможность свободного выбора «субъективных волеизъявлений и действий» [10, с. 208] предполагает необходимость осмысления границ осуществимого. С другой,- целесообразность личной ответственности за все, что он «делает» в мире, со своей жизнью 
и жизнетворением, признавая и ограничивая пределы возможного и желаемого в достижении должного (гармонического).

Наконец, свобода жизнетворения и культура свободы невозможны вне человеческого достоинства и гордости. Следовательно, подлинная суть феномена свободы это и есть обретение человеческого достоинства, морально-нравственного суверенитета личности через полагание человеческого и человечности, того абсолютного «ценностного стандарта» (В. Малахов), который способствует реализации человеческой сущности и проявлению человеческого лика, придает жизненному миру цельность, целостность и ценность.

\section{1 Литература}

[1] Бердяев Н.А. О рабстве и свободе человека / Опыт персоналистической философии. - Париж, 1939.

[2] Библер B.C. От наукоучения - к логике культуры: Два философских введения в двадцать первый век.-М., 1990.

[3] Гадамер Г.Г. Актуальность прекрасного. - М., 1991.

[4] Жизненный путь личности (вопросы теории и методологии социально-психологического исследования). - К., 1987.

[5] История ментальностей, историческая антропология. Зарубежные исследования в обзорах и авторефератах. - М., 1996.

[6] Кизима B. Тотальність і сизигійна «душа» культурних трансформацій // Філософська думка. - 1998. - №1.

[7] Кримсъкий С.Б. Уособлення як шлях самотворення людини // Філософсько-антропологічні читання'95. - К., 1996. - Вип. 1.

[8] Панарин А.С. Смысл истории // Вопр. философии. - 1999. - №9.

[9] Сорокин П. Родовая структура социокультурных явлений // Человек. Цивилизация. Общество. - М., 1992.

[10] Храмова В.Л. Целостность духовной культуры. - К., 1995.

[11] Шевченко И.В. Идея гармонии как принцип человеческого жизнеустроения. Дис. канд. филос. наук. - Кривой Рог, 2004. 